\title{
COLÉGIO NOSSA SENHORA DO AMPARO: CASA DE ORAÇÂO, EDUCAÇÃO E TRABALHO
}

\author{
Maria do Perpétuo Socorro Gomes de Souza Avelino de França ${ }^{1}$ \\ Universidade do Estado do Pará e Universidade da Amazônia \\ Samara Avelino de Souza França ${ }^{2}$ \\ Universidade da Amazônia
}

\section{RESUMO}

O objetivo deste trabalho é analisar como eram educadas as meninas órfãs pobres, desvalidas, expostas e pensionistas do Colégio Nossa Senhora do Amparo, criado em 1804, pelo Bispo Frei Caetano Brandão, na cidade de Belém do Pará. O recorte histórico de análise é o período de 1860 a 1870. Para compreender o universo cultural deste estabelecimento de ensino, valemo-nos dos Regulamentos do Colégio, relatórios dos presidentes da província e dos administradores do Amparo.O presidente da Província era o protetor supremo do Colégio, o qual era mantido por doações de particulares, donativos, esmolas e quantias fixadas pelas Assembléia Geral e Provincial. As alunas iniciavam suas atividades às cinco e meia da manhã. A partir daí, dividiam o seu tempo entre as orações na capela e as aulas. Às nove e meia da noite, recolhiam-se aos dormitórios. As meninas eram educadas para não desperdiçar tempo, evitando, por conseguinte, a ociosidade. Tratava-se de um tempo de educação controlado pelo toque do sino que organizava a rotina do Colégio, indicando o início e o fim de cada atividade. A educação baseada nos princípios do catolicismo buscava formar, no futuro, mães caridosas, bondosas, amáveis a serviço da doutrina católica.

Palavras-Chave: Colégio Nossa Senhora do Amparo, Educação. História

\section{NOSSA SENHORA DO AMPARO SCHOOL: HOUSE OF PRAYER, EDUCATION AND WORK.}

\begin{abstract}
The aim from this research is analyze how were educated the poor, helpless, pensioner and orphaned girls of Nossa Senhora do Amparo School, created in 1804, by the Bishop Frei Caetano Brandão, in the city Belém of Pará. The historical moment of analysis is the period from 1860 to 1870 . To understand the cultural universe of this instruction establishment, were used the school statute and the reports of the Presidents from Province and administrators of Amparo's. The President of the Province was the supreme protector of the School, which was maintained by private donations, alms and amounts fixed by General and Provincial Assembly. The students began their activities at five-thirty in the morning. Thereafter, divided their time between the prayers in the chapel and the classes. At nine-thirty in the night, went to the dormitories. The girls were educated to don't waste time, avoiding, consequently, the idleness. It was a time of education controlled by the bell ring, which organized the school routine, indicating the beginning and the end of every activity. The education based in the principle of Catholicism sought to form, in the future, charitable, loving and kind mothers at service of Catholic doctrine.
\end{abstract}

Key-words: Nossa Senhora do Amparo School. Education. History 


\section{INTRODUÇÃO}

Nos séculos XVIII e XIX, a única forma das famílias pobres no Brasil conseguirem apoio público para a criação de seus filhos era abandonando-os, para que fossem encaminhados a instituições assistenciais existentes no país. As famílias não viam o recurso à assistência como um ato de desamor, mas uma possibilidade de proteger seus filhos do infanticídio. Os dicionários do século XVIII, fazem referência a criança exposta ou criança enjeitada em vez de abandonada; já as leis do início do século XIX empregam freqüentemente a primeira expressão. Na primeira metade deste século, observa-se tímidas aparições nos textos legais da expressão crianças abandonadas, "até se generalizar por volta de 1890. Contudo, a nova terminologia dizia respeito fundamentalmente às crianças infratoras, aos delinquentes, contraventores ou vadios" (VENÂNCIO, 1999, p. 20).

As crianças pobres para serem socorridas pelos hospitais deveriam ser registradas como enjeitadas. Os abrigos que as recebiam, nessa condição, funcionavam nas Santas Casas da Misericórdia. "As casas da Roda não eram asilos; elas simplesmente acolhiam crianças e as enviavam a outras famílias, que recebiam ajuda financeira por conta disso" (VENÂNCIO, 1999, p.52).

No Brasil Colônia, os conventos, e, na ausência destes, os recolhimentos eram os únicos espaços que abrigavam meninas para serem educadas. "Na falta absoluta de um ensino institucional, eles serão, além da instrução doméstica, a única opção educacional para as mulheres da Colônia até o século XIX (ALGRANTI, 1993, p. 247).

Embora os objetivos dessas instituições fossem estabelecidos no momento de suas criações, era na prática cotidiana que se definiam os rumos a serem seguidos pelos que lá viviam. Essas instituições foram moldadas para atender às necessidades das populações locais, contraindo, na maioria das vezes, as próprias normas e estatutos para as quais haviam sido criadas. Na região sudeste, por exemplo, deparamo-nos com conventos servindo de asilos "e refúgio a mulheres da elite e recolhimentos em que as mulheres se mantinham fiéis às normas da vida monástica contemplativa, apesar de não serem casas de religiosas professas" (Idem, p.79).

A falta de instituições escolares para educar mulheres na Colônia contribuiu para que tal espaço fosse aproveitado com finalidades diversas, abrigando mulheres com opções de vida tão distintas.

Na Província do Pará, o Bispo Frei Caetano Brandão criou em 1878, na cidade de Belém, localizada entre os rios Guamá e Amazonas, na região Norte do país, um estabelecimento destinado a atender meninas órfãs e desvalidas, mantido por doações de pessoas caridosas da capital e do interior da província, entretanto, esse espaço educativo teve vida curta. Em 1794, esse frei foi transferido para o arcebispado de Braga, em Portugal.

Ribeiro (2002), analisando a educação feminina no século XVIII em Portugal, traz a discussão, em algumas passagens de seus escritos, o papel desempenhado pelo Arcebispo Frei Caetano Brandão na educação de mulheres no supracitado país. Apoiando-se nos estudos de Peixoto (1991) sobre a atuação desse religioso no campo do ensino, ressalta que ele era grande conhecedor da realidade da educação portuguesa na segunda metade do século XVIII, "nomeadamente o abandono, o analfabetismo e a discriminação pela educação da mulher" (RIBEIRO, 2000, p.54). Enfatiza que o frei foi um defensor do desenvolvimento educacional de mulheres em Portugal, criou vários estabelecimentos de ensino destinados a esse fim - entre eles, o Colégio São Caetano (1791-1991); instalou, no Recolhimento de Tamanca (1798), nas freguesias de São Lazaro e da Sé, vinte escolas de 
ensino para o atendimento de meninas órfãs e desvalidas. A educação proposta visava a formar boas mães e esposas.

O Colégio Nossa Senhora do Amparo, inicialmente denominado de Recolhimento das Educandas, foi criado em 1804 pelo Bispo do Pará, Manoel de Almeida Carvalho, na cidade de Belém do Pará para abrigar meninas índias. Esse estabelecimento foi instalado no dia 10 de junho do mesmo ano em uma casa de aluguel pertencente ao Seminário Episcopal, à Rua do Açougue.

O Presidente da Província do Pará, Fausto Augusto de Aguiar, em 21 de novembro de 1851, expediu os Estatutos do Colégio Nossa Senhora do Amparo. Estabeleceu-se nesse documento que o Recolhimento das Educandas ficava definitivamente criado, com a denominação de Colégio Nossa Senhora do Amparo, tendo por finalidade recolher e educar meninas desvalidas, expostas a cargo da Câmara Municipal e porcionistas. De acordo com os estatutos, o presidente da Província passava a ser o protetor supremo do Colégio Nossa Senhora do Amparo.

Na Primeira República - mais precisamente, em 1897 - o Colégio recebeu o nome de Gentil Bittencourt. Em 1906, no Governo Augusto Montenegro, instalou-se definitivamente na Av. Magalhães Barata, $n^{\circ}$ 137, Bairro de Nazaré, Belém do Pará, num suntuoso edifício, construído em um terreno de $20.393 \mathrm{~m} 2$.

Buscamos, neste texto, analisar como eram educadas as meninas órfãs e desvalidas no Colégio Nossa Senhora do Amparo, no período de 1860 a 1870. Para adentrar o universo cultural da época, valemo-nos dos Regulamentos do Colégio Nossa Senhora do Amparo, dos relatórios dos presidentes da província e dos administradores do colégio, para compreender o processo formativo a que foram submetidas essas meninas no estabelecimento de ensino. Para dar conta desse propósito, trazemos para discussão o cotidiano das alunas, a direção e a administração do Colégio.

\section{A ROTINA DAS MENINAS NO COLÉGIO NOSSA SENHORA DO AMPARO}

Por meio da Portaria de 6 de Agosto de 1860, o Vice-Presidente da Província do Pará, Fábio Alexandrino de Carvalho Reis, determinou que fosse posto em execução provisoriamente o regulamento interno do Colégio Nossa Senhora do Amparo, organizado pelo Administrador.

Segundo consta na referida Portaria, as educandas eram acordadas às cinco horas da manhã, com o primeiro toque do sino. Ás cinco e meia, com o segundo toque, saíam dos seus dormitórios e se dirigiam à capela para as orações da manhã. Após esse momento, algumas educandas retornavam aos dormitórios para arrumá-los, enquanto as demais se dirigiam à sala de estudos, onde permaneciam até às sete e meia da manhã.

A partir deste horário era servido o almoço, presidido pela regente. Na falta dela, que só poderia ocorrer por motivo de doença, essa refeição seria conduzida por uma das mestras, assim como todos os serviços internos. Às oito horas, as meninas deviam ocuparse dos seus de deveres e obrigações escolares. As dez horas as educandas que freqüentavam as escolas se reuniam com a classe de costureiras, trabalhando com elas até as onze e meia da manhã.

Ao meio dia era servido o jantar, devendo as educandas permanecer em silêncio Se uma educanda necessitasse de alguma coisa daria uma pequena pancada na mesa para que as que estivessem trabalhando no refeitório atendessem o seu pedido.Concluído o jantar e dado graças ao Senhor, as educandas eram encaminhadas à sala de recreio, onde se divertiriam até as duas horas da tarde. 
Das quatorze horas às dezessete, as alunas retomavam as suas atividades; ao fim das tarefas se dirigiam para o jardim ou para a sala de recreio, permanecendo neste espaço até às dezoito horas. Com o toque da Ave- Maria, nesse horário, retornavam à capela para rezar. Depois das orações se deslocavam para a sala de estudos, lá, permanecendo até às vinte horas e meia. A partir deste horário era servida a ceia, no fim da qual as alunas agradeciam ao Senhor e voltavam à sala de recreio, permanecendo ali até às vinte e uma horas e meia. Com o toque de recolher, nessa mesma hora, elas retornavam aos seus dormitórios, de onde só sairiam no dia seguinte com o toque do alvorecer.

A cada toque do sino, representava o início e o fim de uma atividade. As alunas eram educadas para utilizar o máximo possível do tempo, evitando seu desperdício e a ociosidade. O tempo, portanto, era controlado rigorosamente, sendo punidas as alunas que faltassem ou se atrasassem no cumprimento de suas tarefas.. O sino, portanto, funcionava como agente organizador da rotina do Colégio. "A vida no interior dos claustros tinha seu ritmo marcado pelas badaladas do sino. O tempo escoava lentamente entre um toque e outro, alertando as reclusas quando iniciar ou concluir uma atividade. '’(ALGRANTI,1999, p. 192).

O sino, portanto, dividia as horas do dia e da noite, do tempo individual do tempo coletivo e cumpria a função de disciplinar o cotidiano das educandas.

Há muito tempo, processos disciplinares já se faziam presentes nos conventos, nos exércitos e nas oficinas, mas somente no decorrer dos séculos XVII e XVIII tornaram-se fórmulas de dominação. A disciplina, nesse tempo, tinha a função maior de "adestrar" e distribuir os indivíduos nos espaços. Os lugares por eles ocupados não são determinados apenas para satisfazer à necessidade de vigiar, mas de impedir as comunicações "perigosas"' e criar um espaço útil de trabalho.

Foucault (1987) ao analisar a disciplina nas escolas militares observa que suas estruturas haviam sido pensadas para facilitar a vigilância dos alunos. Os quartos dispostos ao longo dos corredores constituíam uma série de celas vigiadas por um oficial superior que controlava o comportamento dos futuros soldados. "As instituições disciplinares produziram uma maquinaria de controle que funcionou como um microscópio do comportamento [...] formaram, em torno dos homens, um aparelho de observação, de registro e de treinamento (FOUCAULT, 1987, p.145).

De acordo com o regulamente do Colégio Amparo, a regente, descrita como mulher bondosa e rigorosa, nomeava semanalmente educandas para trabalharem no refeitório, cabendo a elas cozinhar, cuidar da organização e limpeza das mesas e servir às educandas. Além disso, designava meninas para servirem como enfermeiras e outras para cuidar da limpeza dos dormitórios. Nos domingos e dias santos, as educandas dedicavam-se à oração, missa pela manhã na capela, leitura de livros religiosos ou de estatutos e regras.

As pessoas para adentrarem no Colégio teriam que ter autorização do administrador. Parentes e responsáveis que obtivessem permissão para visitar as educandas não poderiam passar da sala de espera, exceto, se as alunas estivessem doentes, as quais também eram proibidas de enviar e receber cartas, salvo quando autorizadas pela regente. Da mesma forma, elas deveriam respeitar as suas superioras, sendo proibidas de utilizar expressões ofensivas ao administrador, às mestras, a regente e também a outras educandas.

A organização das turmas, o cuidado com a higiene, uniformes, saúde, alimentação das educandas, assim como o cumprimento de cada atividade no tempo designado, visitação das salas de aula e às alunas doentes, castigo àquelas que faltassem com suas obrigações, hora de recolhimento, arrecadação dos materiais necessários ao Colégio (objetos de costura, alimentos, uniformes, medicamentos), em suma, a manutenção da boa ordem no Amparo e a formação moral das alunas ficavam a cargo da regente, a qual 
deveria também comunicar ao administrador, por meio de relatórios, sobre o funcionamento e situação do Colégio.

Os castigos impostos às educandas que descumprissem o regulamento do Colégio eram: ficar de joelho durante as aulas, ser privadas do recreio ou ainda ser enviadas para a casa de correção, onde não poderiam falar com ninguém, devendo decorar, escrever lições ou costurar. As educandas reincidentes deveriam ser expulsas do Colégio Nossa Senhora do Amparo.

As educandas deveriam ouvir com olhos baixos os conselhos e repreensões dos seus superiores. Os gestos, repletos de simbolismos, "o tom de voz, as genuflexões e os movimentos do corpo eram julgados pela comunidade com rigor" (ALGRANTI, 1999, p. 195). O silêncio era visto como virtude, principio maior de vida. Além disso, pregava-se, através dos ensinamentos do capelão, o amor ao trabalho, gerência doméstica, caridade, submissão e obediência. Assim, procurava-se formar mães caridosas e amáveis a serviço do catolicismo

O Colégio Nossa Senhora do Amparo, de acordo com o Regulamento de 9 de abril de 1869, tinha por fim proteger e educar meninas órfãs pobres, desvalidas e expostas. $\mathrm{O}$ estabelecimento podia atender também a meninas porcionistas, cujos pais, parentes ou tutores podiam pagar pelos ensinamentos lá ofertados uma pensão de $50 \$ 000$ réis a cada trimestre. As vagas destinadas para essa categoria não poderiam exceder a 50.

O Colégio era mantido pelas rendas resultantes da doação de bens particulares, donativos e esmolas, além de quantias fixadas pelas Assembléias Geral e Provincial. A educação e a proteção das educandas eram consideradas os verdadeiros fins do Colégio.

As alunas contribuintes recebiam de seus responsáveis legais um enxoval com mais de vinte peças para uso diário e para passeio. Os cofres da província forneciam às alunas pobres o mesmo enxoval. Algumas peças para uso diário eram: vestidos de chita escura (4); saias de madapolão (4); lenços de mão (4); fronhas (4), travesseiro (1); pente de alisar (1); bacia para rosto (1) e urinol (1). Para sair, incluíam-se itens como vestido de cambraia lisa (1); botinas (1 par); pente de cabeça (1), dentre outros.

Seriam admitidas no Colégio meninas expostas e órfãs sem parentes que pudessem garantir sua sobrevivência e educação; filhas de indivíduos presos e pobres e órfãs de pai militar ou empregado público, reconhecidamente necessitado. Além dessas condições, as alunas deveriam ter idade entre 6 a 12 anos e não sofrer de doença contagiosa. As 150 alunas protegidas pelo Colégio foram distribuídas pelo Presidente da Província nas seguintes comarcas, conforme o quadro a seguir:

Quadro 1.Distribuição de vagas pelas comarcas da Província

\begin{tabular}{|c|c|}
\hline CAPITAL & 65 \\
\hline CAMETÁ & 20 \\
\hline BREVES & 12 \\
\hline MARAJÓ & 11 \\
\hline SANTARÉM & 10 \\
\hline BRAGANÇA & 8 \\
\hline ÓBIDOS & 8 \\
\hline GURUPÁ & 8 \\
\hline MACAPÁ & 8 \\
\hline TOTAL & $\mathbf{1 5 0}$ \\
\hline
\end{tabular}

Fonte: Regulamento do Colégio Nossa Senhora do Amparo Pará, 1869. p.28 
De acordo com o Regulamento de 1869, as meninas eram distribuídas em classes, enturmadas por idade e adiantamento nos estudos. As educandas de faixa etária de seis a oito anos frequentavam a sala de asilo, sendo instruídas em preceitos religiosos e morais; conhecimento das letras do alfabeto, dos seus diferentes caracteres, dos sons e das modificações, das silabas e das palavras; leitura fácil; pronúncia correta; noções de aritmética, no que diz respeito à formação de números simples e sua representação por letras arábicas e operações de somar, diminuir e tabuada; costura lisa, ponto de marca e crochê.

As educandas maiores de oito anos deixavam a sala de asilo para dedicarem-se à sala de lavor e à escola. Na sala de lavor, ensinavam-se prendas, como a costura e o corte de roupas e o bordado, sendo três mestras responsáveis em passar esses ensinamentos à tarde as educandas. A Comissão Protetora era responsável por adquirir os materiais utilizados nas aulas e vender a produção. Os recursos arrecadados eram revertidos em prol das educandas.

$\mathrm{Na}$ escola do Colégio, as alunas aprendiam leitura, escrita e caligrafia; aritmética; gramática nacional; noções de história e geografia do Brasil; leitura comentada do evangelho e história sagrada; francês e prendas. A sala de lavor funcionava à tarde, e a escola, de manhã.

As alunas que se destacavam por seu bom comportamento e amor ao trabalho tinham seus nomes escritos em uma lista de honra, sendo três prêmios entregues anualmente àquelas que fossem dignas de recebê-los. Em contrapartida, as que transgredissem as regras eram punidas pela Regente e pelas Mestras, que podiam aplicar as seguintes penalidades: leitura em voz alta; isolamento do convívio com as colegas; ficar em pé enquanto as demais estivessem sentadas; privação do recreio ou duplicação de seu trabalho no Colégio.

Ainda de acordo com o Regulamento de 1869, as alunas, ao completarem dezoito anos, tinham que deixar o Colégio. A saída se realizava mediante casamento, locação em casa de famílias honestas, reclamos dos pais ou tutores e emprego nas escolas públicas.

As educandas desvalidas que se casavam com a autorização do Presidente da Província recebiam um enxoval no valor de 500\$000 réis. Depois de casadas recebiam ainda um dote de $1.000 \$$ réis, que era entregue ao marido pelo administrador do Colégio. $\mathrm{O}$ enxoval de casamento das educandas compreendia peças de vestuário e de cama e mesa. Eram eles: brinco de ouro (1 par); vestido de seda branca (1); vestido de riscado ou chita (4); camisas de madapolão (12); saias e um vestido de baixo (3); lenços de mão (6); lenços de seda para pescoço (2); luvas de pelica branca (1 par); grinalda branca (1); lenços de madapolão (6); lenços de linho (4); toalhas de Bretanha para rosto (6); coberta de chita (1); fronhas (2 pares); meias finas (6); sapatos, sendo um par de seda branca e outros de duraque (4) e baú para roupa (1).

As seis primeiras desvalidas que se casavam em cada ano recebiam essas dotações. Os dotes das órfãs das casas dos expostos, de misericórdia ou beneficência eram concedidos pelas respectivas casas.

As verbas destinadas aos dotes provinham do tesouro provincial e de doações de particulares. Havia, na entrada do estabelecimento, um pequeno cofre, denominado de Cofre da Beneficência para receber as doações. Os dotes eram concedidos primordialmente a órfãs pobres.

Para o Presidente da Província do Pará, João Alfredo Corrêa de Oliveira (1870), as medidas estabelecidas no Regulamento de 1869 para que as alunas deixassem o Colégio ao completarem 18 anos eram ineficazes. Para ele, os dotes concedidos às educandas não se constituíam em atrativos para os rapazes interessados em contrair matrimônio, pois eram 
muito modestos. Por outro lado, entregar as educandas aos parentes era praticamente impossível, já que não os tinham. Empregá-las em escolas públicas como professoras de primeiras letras esbarrava na legislação em vigor, que exigia dos candidatos ao magistério a idade de 21 anos. Restava apenas o contrato de locação de serviço, mas como fazê-lo, se as famílias não se sentiam atraídas em admiti-las para trabalharem em suas casas?

Para empregar em casas de famílias mais de vinte órfãs pobres, o referido presidente nomeou uma comissão para promover os contratos de locação de serviço. A comissão não conseguiu realizar esse intento e o presidente foi duramente criticado por alguns segmentos da sociedade paraense, que viam no ato de João Alfredo humilhação e desonra.

A comissão, então, propôs ao presidente a criação de um asilo para amparar as jovens ao completarem 18 anos. Apesar de essa proposta ter sido bem aceita pelos presidentes subsequentes como a única solução para a crise instalada, não chegou a ser concretizada entre os anos de 1860 e 1870. Isso talvez explique o elevado número de alunas no colégio.

Leila Mezan Algranti (1996), no texto A Irmandade da Santa Casa de Misericórdia do Rio de Janeiro e a Concessão de Dotes (1808-1822), analisando a concessão de dotes nessa instituição, ressalta que a prática de dotação de dote, mais do que um costume da caridade medieval cristã, revela a imagem que a sociedade da época possuía em relação à mulher e ao casamento. O dote representava para quem o recebia, uma segurança futura e um auxílio para conquistar um noivo. Ser órfã, pobre, pura e virtuosa eram os requisitos básicos para a concessão do dote, que, mesmo sendo modesto, atraia os futuros esposos. "O casamento para a recolhida era a realização máxima dos objetivos e dos princípios para os quais fora preparada [...] assumir os papéis de mãe e boa dona-de-casa, habilidosa nos trabalhos manuais e honrada (ALGRANTI, 1996, p.63).

\section{DIREÇÃO E ADMINISTRAÇÃO DO COLÉGIO NOSSA SENHORA DO AMPARO}

Segundo o Regulamento de 1869, a Direção Geral do Colégio era exercida pelo Presidente da Província, a quem competia dirigir, inspecionar e fiscalizar $\mathrm{o}$ estabelecimento; nomear e demitir os empregados; admitir e retirar as educandas do Colégio. A administração interna era confiada a um administrador e a uma regente. Contava, ainda, o colégio com uma Comissão Protetora - constituída de senhoras escolhidas pelo Presidente da Província - Capelão, Médico, Mestra de Costura, Professoras e Professores de Primeiras Letras.

O Administrador devia ser uma pessoa de reconhecida moralidade, ter mais de trinta e cinco anos e exercer o cargo de forma gratuita, a serviço de Deus e de Nossa Senhora do Amparo. Todos os empregados do estabelecimento eram subordinados a ele. Sua função principal era garantir o cumprimento dos regimentos ou disposições relativas ao colégio, bem como fazer cumprir as ordens do Presidente da Província.

Ele também tinha o papel de inspecionar o trabalho da regente, das mestras e de professores e professoras, a fim de que a educação promovida no Colégio fosse de elevada qualidade e perfeição, bem como de administrar as doações recebidas pelas educandas. Por fim, encaminhava, anualmente, um relatório ao Presidente da Província, informando sobre oadiantamento das educandas, opinando sobre o comportamento e obediência dos empregados e os negócios referentes ao colégio, com também o número de educandas 
matriculadas, suas idades, as comarcas a que pertenciam, as que se casaram, além da entrada e saída de benfeitorias.

A regente era encarregada de dirigir internamente o colégio. Esse cargo era confiado pelo Presidente da Província a uma mãe de família dotada de bons costumes e moralidade. Suas principais funções eram zelar pela conduta dos empregados e das educandas; adverti-los e repreendê-los quando deixavam de cumprir com os seus deveres; zelar pela limpeza do prédio, pela conservação dos móveis, das camas e do vestuário das alunas e acompanhar os seus ensinamentos. Logo, à regente, competia garantir o bom funcionamento do colégio e preparar as educandas para a vida doméstica, ensinando- as os afazeres da casa e zelando por sua saúde.

As Mestras deveriam residir no Colégio, devendo ser pessoas instruídas, de boa moral e costumes. É válido lembrar que, enquanto não se dispunha de pessoal nessas condições poderão ser admitidas mestras externas.

A obrigação das mestras girava em torno do trabalho doméstico - mais precisamente, do ensino da costura, do bordado, de lavar e engomar roupas, de cozinhar e de fazer doces. Elas ensinavam às alunas várias especialidades que pudessem ajudá-las a conseguir um emprego na sociedade e a garantir suas sobrevivências ao saírem do Colégio. Além disso, ensinavam os valores religiosos da piedade, do amor a Deus e ao próximo e da dedicação ao trabalho.

As mestras, juntamente com a regente, deveriam zelar pelo cumprimento das ordens referentes à administração, à economia e à fiscalização interna do colégio, devendo informar à regente, por meio de documento escrito, a situação de suas disciplinas, o regimento interno da escola, as disposições da instrução pública e também um mapa contendo o estado de adiantamento das educandas.

O ensino no Colégio estava a cargo de três mestras de prendas domésticas, de três professoras de primeiras letras da $1^{\mathrm{a}}$, da $2^{\mathrm{a}}$ e da $3^{\mathrm{a}}$ classes e de um mestre ou mestra de piano.

A Comissão Protetora era responsável, essencialmente, pela caridade e pela proteção das órfãs e desvalidas, devendo informar ao Presidente da Província, por intermédio do Administrador, as irregularidades encontradas no Colégio. À Comissão competia visitar semanalmente ou mensalmente o estabelecimento; cuidar para que as educandas andassem vestidas decentemente; adquirir matéria prima para o trabalho das alunas, promovendo a venda, e colher donativos ao Colégio.

O médico visitava diariamente a Instituição para tratar das educandas doentes e para vaciná-las, cabendo a ele organizar um relatório sobre as doenças a que foram acometidas as alunas e as medidas tomadas para evitar novos contágios. Ao Capelão do Colégio competia realizar missa na capela aos domingos e dias santos e ensinar os valores religiosos e morais às alunas.

O Administrador do colégio, José da Gama Malcher, no relatório de $1^{\circ}$ de Julho de 1868, ressaltava que o estabelecimento contava com um número significativo de empregados que garantia o seu funcionamento. O pessoal interno era constituído por uma regente, uma sub-regente, uma mestra de costura, uma ajudante de costura, duas mestras de primeiras letras e duas serventes. O externo, por uma mestra de primeiras letras, uma mestra de música e piano, um mestre de música e piano, um mestre de inglês, um mestre de francês, um médico, um capelão e um fiel. Os ordenados de cada um desses empregados podem ser visualizados no quadro abaixo. 
Quadro 2. Funcionários do Colégio Nossa Senhora do Amparo e seus respectivos Salários

\begin{tabular}{|c|c|c|}
\hline PROFISSÃO & PESSOAL INTERNO & SALÁRIOS \\
\hline REGENTE & D. Anna Maria Serzedelo Faria & $1: 200 \$ 000$ \\
\hline SUB-REGENTE & Vago & $1: 000 \$ 000$ \\
\hline MESTRA DE COSTURA & D. Anna Serzedelo Faria & $800 \$ 000$ \\
\hline AJUDANTE DE MESTRA DE COSTURA & D. Virginia Francisca Guerreiro & $500 \$ 000$ \\
\hline MESTRA DE PRIMEIRAS LETRAS & D. Inez Pastana de Vasconcellos & $450 \$ 000$ \\
\hline MESTRA DE PRIMEIRAS LETRAS & Emília Simplício Gomes de Amaral & $450 \$ 000$ \\
\hline SERVENTE & D. Josefa Ferreira Bello de Souza & $240 \$ 000$ \\
\hline \multirow[t]{2}{*}{ SERVENTE } & D. Ana Justiniana de Souza & $240 \$ 000$ \\
\hline & PESSOAL EXTERMO & \\
\hline MESTRA DE PRIMEIRAS LETRAS & D. Francisca Cândida Benjamin & $1: 400 \$ 000$ \\
\hline MESTRA DE MÚSICA ME PIANO & D. Idalina Amélia França & $1: 000 \$ 000$ \\
\hline MESTRA DE MÚSICA E PIANO & Joaquim Pinto de França & $1: 000 \$ 000$ \\
\hline MESTRE DE INGLÊS & Carlos Kitzinger & $800 \$ 000$ \\
\hline MESTRE DE FRANCÊS & Vago & $800 \$ 000$ \\
\hline MÉDICO & Dr. Camilo José do Valle Guimarães & 1:000\$000 \\
\hline CAPELÃO & Cônego Luiz Barros de Bastos & $800 \$ 000$ \\
\hline FIEL & Antônio Dias Guerreiro Junior & $900 \$ 000$ \\
\hline TOTAL & & $12: 640 \$ 000$ \\
\hline
\end{tabular}

Fonte: PARÁ (1868).

Comparando-se os vencimentos das mestras externas aos das internas de primeiras letras, nota-se uma diferença substancial. As primeiras ganhavam o triplo das últimas. $\mathrm{O}$ que pode ter gerado essa diferença? As fontes pouco dizem a esse respeito, mas podemos inferir que a diferença salarial se deva aos fatos de residirem no colégio e terem concluído, lá, seus estudos como pensionistas.

Segundo o Administrador, José da Gama Malcher (1868), estudavam no Colégio 150 educandas, sendo 120 pensionistas, 1 depositada, 1 agregada e 21 porcionistas. As 120 pensionistas eram provenientes das Comarcas da Capital (94), de Cametá (6), de Santarém (2), do Marajó (7), de Bragança (1), de Gurupá (3), de Macapá (4) e de Óbidos (3). O orçamento aprovado para o colégio para 1869 foi de 34:0000\$000 reis, mas a despesa foi de 36:465\$000, resultando em déficit de 2:465,000 reis, que se deu em decorrência do aumento dos gêneros alimentícios, como manteiga, pão, farinha e galinha. 


\section{CONSIDERAÇÕES FINAIS}

O Colégio Nossa Senhora do Amparo tinha por escopo proteger e educar as meninas órfãs e pobres, as desvalidas, as expostas a cargo da Câmara Municipal e as porcionistas. Quanto ao ensino, as educandas eram divididas em classes a partir de sua idade e adiantamento nos estudos. A educação distribuía-se nas salas de asilo, lavor e escola de primeiras letras.

O Colégio era mantido por meio de rendas decorrentes de aluguéis de casas e terrenos, da doação de bens de particulares e de verbas da Assembléia Provincial. Os recursos financeiros arrecadados pelo estabelecimento não eram suficientes para cobrir as suas despesas que aumentavam a cada ano. Nem mesmo os artefatos produzidos pelas alunas para serem comercializados foram suficientes para equilibrar as finanças.

As alunas iniciavam suas atividades às cinco e meia da manhã. A partir daí, dividiam o seu tempo entre as orações na capela, as aulas na sala de asilo, de lavor, de primeiras letras e os serviços domésticos. Às nove e meia da noite, recolhiam-se aos seus aposentos.

Numa sociedade em que a educação da mulher era predominantemente doméstica, o Colégio Nossa Senhora do Amparo apresentava-se como uma das poucas opções em que as meninas pobres/órfãs e desvalidas tiveram acesso a alguma instrução.

\section{REFERÊNCIAS}

ALGRANTI, Leila Mezan. Honradas e Devotas: mulheres da Colônia: Condição feminina nos conventos e recolhimentos do Sudeste do Brasil, $2^{\text {a }}$ ed, Rio de Janeiro: José Olímpio, 1999.

A Santa Casa de Misericórdia do Rio de Janeiro e a concessão de dotes. In Cadernos Pagu - de trajetórias e sentimentos, Núcleo de Estudos de Gênero. Unicamp, Campinas, n 1, p. 45-66, 1994. Disponível em www.pagu.unicamp.br. Acesso em: 05 jan. 2011.

BEZERRA NETO, José Maia. O Recolhimento das Educandas: uma breve notícia documental (1840). Cadernos Pagu (UNICAMP), Campinas, n. 8/9, 1997.

DEL PRIORE. Mary. O cotidiano da criança livre no Brasil entre a Colônia e o Império In. DEL PRIORE. Mary (org).História das crianças no Brasil. São Paulo: Contexto, 1999.

FIGUEIREDO, Aldrin Moura. Memórias da infância na Amazônia. In. DEL PRIORE. Mary (org). História das crianças no Brasil. São Paulo: Contexto,1999

FOUCAULT, Michel. Vigiar e punir: nascimento da prisão. Petrópolis: Vozes, 1987.

HILSDORF, Maria Lúcia Spedo. Tão longe, tão perto. As meninas do seminário. In STEPHANOU, Maria, BASTOS, Maria Helena Camara (orgs). Histórias e memórias da educação no Brasil, vol.II: século XIX, Petrópolis, RJ: Vozes, 2005 
MANOEL, Ivan Aparecido. Igreja e educação feminina (1859-1919): uma face do conservadorismo, 2 ed.,Maringá:Eduem, 2008.

NUNES, Maria José Rosado. Freiras no Brasil. In DEL PRIORE, Mary.(org). História das Mulheres no Brasil,7ed., São Paulo: Contexto, 2004

PARÁ. Portaria de 6 de Agosto de 1860. Manda por em execução provisioriamente o regulamento interno do Colégio Nossa Senhora do Amparo. In Coleção das Leis da Província do Grão Pará, Tomo XXII, Tipografia de Frederico Carlos Rhossard,1862.

PARÁ. Portaria de 9 de Abril de 1869, da novo Regulamento do Colégio Nossa Senhora do Amparo In Coleção de Leis da Província do Grão Pará, Tomo XXXI, Tipografia do Diário do Grão Pará, 1869.

Lei $\mathrm{n}^{\mathrm{o}} 205$, de 2 de novembro de 1851 manda observar os Estatutos do Colégio de Nossa Senhora do Amparo da Cidade de Santa Maria do Grão Pará. In Coleção de Leis da Província do Grão Pará, Tomo XIII, Tipografia do Diário do Grão Pará, 1851.

Discurso dirigido a Assembléia Legislativa Provincial pelo presidente da Província do Pará, João Maria de Moraes, na abertura da segunda sessão da quarta legislatura da Assembléia Provincial no dia 15 de agosto de 1845. Pará, Tipografia de Santos \& filhos, 1845.

Discurso dirigido a Assembléia Legislativa Provincial pelo presidente da Província, Bernardo de Souza Franco, no dia 15 de agosto de 1839. Pará: Tipografia. de Santos e Menor, 1839.

.Relatório apresentado a Assembléia Legislativa Provincial, pelo quarto VicePresidente, Abel Graça, na primeira sessão da $17^{\circ}$ legislatura. Pará. Tipografia do Diário do Grão Pará, 1870.

Relatório apresentado a Assembléia Legislativa Provincial, pelo Presidente da Província João Alfredo Corrêa de Oliveira, passando a administração a quarto VicePresidente Abel Graça, n dia 17 de Abril de 1870, Tipografia do Diário do Grão Pará, 1870.

Relatório do Administrador do Colégio Nossa Senhora do Amparo, José da Gama Malcher, de 14 de Junho, 1868.

Discurso dirigido a Assembléia Legislativa Provincial pelo presidente da Província, Bernardo de Souza Franco, na abertura da Assembléia Legislativa Provincial, no dia 14 de abril de 1842. Pará, Tipografia de Santos e menor, 1842.

Governo do Estado. A instrução pública no Estado do Pará em 1890. Relatório apresentado ao exmo. Sr Dr. Justo Chermont Leite - governador do Estado, por José Veríssimo, diretor geral da instrução pública. Pará: Tipografia de Tavares Cardoso, 1891. 
RIBEIRO, Arilda Ines Miranda. Vestígios da educação feminina no século XVIII em Portugal. São Paulo: Arte \& Ciência, 2002.

. Mulheres educadas na Colônia. In LOPES, Eliana Marta Teixeira, FARIA FILHO, Luciano Mendes, VEIGA, Cynthia Greive (orgs) 500 anos de educação no Brasil, Belo Horizonte: Autêntica, 2000.

RIZZINI, Irma. Pequenos trabalhadores no Brasil. In DEL PRIORE. Mary (org). História das crianças no Brasil. São Paulo: Contexto,1999

SANTOS, Gisele do Socorro Neves, COSTA, Tânia de Cássia da Silva Costa. Educação de mulheres no século XIX: o Colégio Nossa Senhora do Amparo (Trabalho de Conclusão de Curso- Licenciatura Plena em Pedagogia), Belém, 2008.

SOUZA, Lorena Rafaela Gusmão, BRIGIDA, Shirley Sandra Modesto Santa. Educação feminina em Belém do Pará: O Colégio Gentil Bittencourt. (Trabalho de Conclusão de Curso- Licenciatura Plena em Pedagogia), Belém, 2009.

VENÃNCIO. Renato Pinto. Famílias abandonadas: assistência à crianças de camadas populares no Rio de Janeiro e em Salvador - Séculos XVIII e XIX. Campinas, SP: Papirus, 1999.

VIANNA, Arthur. O Instituto Gentil Bittencourt, Imprensa oficial do Estado do Pará, Belém, 1906

VILLELA, Heloisa de O. S. O mestre escola e a professora. In LOPES, Eliana Marta Teixeira, FARIA FILHO, Luciano Mendes, VEIGA, Cynthia Greive (orgs) 500 anos de educação no Brasil, Belo Horizonte: Autêntica, 2000.

VILLELA, Heloisa de O. S. O mestre escola e a professora In LOPES, Eliana Marta Teixeira, FARIA FILHO, Luciano Mendes, VEIGA, Cynthia Greive (orgs) 500 anos de educação no Brasil, Belo Horizonte: Autêntica, 2000.

Notas

${ }^{1}$ Doutora em História, Filosofia e Educação pela Universidade de Campinas (UNICAMP). Professora do programa de Pós-Graduação em Educação da Universidade do Estado do Pará, docente da Universidade da Amazônia. Coordenadora do grupo de Pesquisa História da Educação na Amazônia (GHEDA). E-mail: socorroavelino@hotmail.com

${ }^{2}$ Acadêmica do Curso de Direito da Universidade da Amazônia. E-mail: Samara avelino@ hotmail.com

Recebido em: $\quad$ 26/07/2011

Aprovado em: 30/07/2011 